\title{
Non-typhoidal Salmonella serovars in poultry farms in central Ethiopia: prevalence and antimicrobial resistance
}

\author{
Tadesse Eguale(10
}

\begin{abstract}
Background: Poultry is one of the common sources of non-typhoidal Salmonella and poultry products are the major sources of human infection with non-typhoidal Salmonella. In spite of flourishing poultry industry in the country, data on prevalence and antimicrobial susceptibility of non-typhoidal Salmonella serovars at farm level is not available in Ethiopia. This study investigated prevalence, serotype distribution and antimicrobial resistance of non-typhoidal Salmonella in poultry farms in Addis Ababa and its surrounding districts.
\end{abstract}

Results: A total of 549 fresh pool of fecal droppings ( $n=3$ each) were collected from 48 poultry farms and cultured for Salmonella using standard laboratory technique and serotyped using slide agglutination technique. Susceptibility of Salmonella isolates to18 antimicrobials was tested according to CLSI guideline using Kirby-Bauer disk diffusion assay. Salmonella was recovered in 7 (14.6\%) of the farms and 26 (4.7\%) of the samples. Salmonella was more common in poultry farms with larger flock size than in the smaller ones and in Ada'a district as compared to other districts. All isolates were obtained from farms containing layers. Two out of 6 (33.3\%) farms that kept birds in cage were positive for Salmonella while only 5 (11.9\%) of the 42 farms who used floor system were positive. Oxytetracycline was used widely in 40 (83.3\%) of the farms, followed by amoxicillin 14 (29.2\%) and sulfonamides 11 (22.9\%). Salmonella Saintpaul was the dominant serotype detected accounting for 20 (76.9\%) of all isolates. Other serovars, such as S. Typhimurium3 (11.5\%), S. Kentucky 2 (7.7\%) and S. Haifa 1 (3.8\%) were also detected. Of all the Salmonella isolates tested, 24 (92.3\%) were intermediately or fully resistant to sulfisoxazole and streptomycin, 12 (46.2\%) to cephalothin, while 11 (42.3\%) were resistant to ampicillin, amoxicillin+clavulanic acid, kanamycin and chloramphenicol. Multidrug resistance (MDR) to several drugs was common in S. Kentucky and S. Saintpaul.

Conclusion: Despite low prevalence of Salmonella in poultry farms in the study area, circulation of MDR strains in some farms warrant special biosecurity measures to hinder dissemination of these pathogens to other farms and the public. Moreover, awareness creation on prudent use of antimicrobials is recommended.

Keywords: Poultry, Non-typhoidal Salmonella, Antimicrobial resistance, Prevalence, Ethiopia

\section{Background}

Salmonella is one of the major causes of food-borne diseases worldwide [1]. Poultry and other food animals are considered the common reservoirs of Salmonella enterica and undercooked poultry products are the major sources of human infection with non-typhoidal Salmonella [2, 3]. Several host unrestricted S. enterica serovars frequently isolated from poultry without

Correspondence: tadesse.eguale@aau.edu.et

Aklilu Lemma Institute of Pathobiology, Addis Ababa University, P.O. Box 1176, Addis Ababa, Ethiopia showing any clinical signs usually infect a wider range of hosts and cause disease in humans as well [4].

It has been shown that some of the most commonly detected serovars in chickens in a given geographic area are also among the top serovars associated with human infections indicating the role of Salmonella colonization of poultry farms to public health [5]. Knowledge on distribution of Salmonella serovars in food animals and humans is useful to understand the trends of Salmonella epidemiology and to identify serovars that cluster over time and space. Temporal and spatial variation in rate

(c) The Author(s). 2018 Open Access This article is distributed under the terms of the Creative Commons Attribution 4.0 International License (http://creativecommons.org/licenses/by/4.0/), which permits unrestricted use, distribution, and 
and distribution of Salmonella serovars in poultry industry has been reported $[2,6]$.

Developed countries conduct routine surveillance of Salmonella in poultry farms to understand the level of colonization by Salmonella, serovars involved and drug resistance profile with the aim of designing ways of reducing public health salmonellosis of poultry origin $[7,8]$. However, in developing countries like Ethiopia, little effort is made to monitor Salmonella in poultry farms and information on prevalence and serotype distribution as well as phenotypic and genotypic relatedness of Salmonella isolated from poultry and humans is not well documented. Local knowledge on prevalence of Salmonella, serotype distribution and associated risk factors is important to implement appropriate control strategy to reduce wider dissemination of important zoonotic serovars [2].

There is little available literature on farm level prevalence and serotype distribution of non-typhoidal Salmonella in poultry farms in Ethiopia. Previous studies conducted on retail raw chicken products reported 17.9\% prevalence of Salmonella, the dominant serovars being $S$. Braenderup (31.5\%), S. Anatum (25.9\%), S. Saintpaul (14.8\%) and S. Uganda (11.1\%) [9]. Another study also reported that $14 \%$ of chicken carcass from supermarkets in Addis Ababa were positive for Salmonella. S. Braenderup (41.4\%), S. Hadar (20.7\%), S. Newprt $(13.8 \%)$ and $S$. Typhimurium (10.3\%) were the dominant serovars detected in poultry products in Addis Ababa [10]. However, source of Salmonella contamination in these poultry products could be either from farm or due to cross contamination during slaughter, transportation or storage. Recent study in southern Ethiopia showed that $16.7 \%$ of samples from poultry and the environment of three poultry farms were positive for Salmonella although this study did not show whether Salmonella isolates were host specific Salmonella serovars or host unrestricted non-typhoidal Salmonella serovars [11].

Majority of the Salmonella isolates from poultry products and poultry farms in the previous studies were found to be resistant to several antimicrobials. Information on farm level prevalence and antimicrobial susceptibility status of isolates can explain the level of public health risk associated with poultry products. The aim of this study was therefore to determine the prevalence, serotype distribution and antimicrobial resistance of salmonella in poultry farms in central Ethiopia. The type of antimicrobials and disinfectants commonly employed in poultry farms were also assessed.

\section{Methods}

\section{Study design, study area and study animals}

A cross-sectional study was conducted in Addis Ababa and 3 districts of Oromia region located at the outskirt of Addis Ababa from July 2013-January 2014. A total of 549 pooled fresh fecal droppings (from 3 chicken each) were collected in 48 farms (Ada'a district $n=$ 33, Addis Ababa $n=6$, Sebeta $n=6$, Barake $n=3$ ). Inclusion of farms in the sampling was based on representation of the area under study, willingness of the owners, availability of poultry farms in the study area, and the flock having a minimum of 50 birds. Most of the poultry farms investigated in the current study were those from Ada'a district due to large number of poultry farms in this district.

\section{Data and sample collection}

Information such as type of poultry farm, whether it is broiler or layer, flock size, birds housing system, age of birds, purpose and types of antimicrobials and disinfectants commonly used in the farm during the last 6 months were recorded using a purposively designed questionnaire. Collection of data was performed at the time of fecal sample collection from each farm. Pooled fresh fecal droppings(from 3 chickens) were collected using clean disposable gloves in to sterile zippered plastic bags which were transported to microbiology laboratory of Aklilu Lemma Institute of Pathobiology, Addis Ababa University in an ice box within 3-4 h of collection.

\section{Salmonella isolation, identification, serotyping and phage typing}

Salmonella isolation and identification was carried out using conventional methods [12, 13]. Briefly, fresh fecal droppings from three chicken was thoroughly mixed of which $10 \mathrm{~g}$ of feces was suspended in $90 \mathrm{ml}$ of buffered peptone water (BPW) (Becton Dickinson, Sparks, MD) and incubated overnight at $37{ }^{\circ} \mathrm{C}$. Enrichment, culturing on selective media, and biochemical analysis of presumptive Salmonella colonies was conducted as shown previously [14]. Genus specific PCR was used to confirm isolates suspected to be Salmonella by biochemical tests [15]. Salmonella Typhimurium (ATCC 14028) was used as a positive control during biochemical analysis and PCR. Confirmed Salmonella isolates were stored at $-80{ }^{\circ} \mathrm{C}$ in $20 \%$ glycerol till further investigation.

Serotyping and phage typing of Salmonella isolates was conducted at the World Organization for Animal Health (OIÉ) Reference Laboratory for salmonellosis, Public Health Agency of Canada's National Microbiology at Guelph. Determination of serovars was conducted using serum agglutination technique as shown previously $[16,17]$, based on identification of somatic $(O)$ antigens [18] and flagellar (H) antigens [19]. 


\section{Antimicrobial susceptibility testing}

Isolates were investigated for susceptibility to 18 antimicrobials using the Kirby-Bauer disk diffusion method according to Clinical and Laboratory Standards Institute guidelines [20]. Antimicrobials used in the current study were amikacin $(30 \mu \mathrm{g})$, amoxicillin + clavulanic acid (20/ $10 \mu \mathrm{g})$, ampicillin $(10 \mu \mathrm{g})$, cefoxitin $(30 \mu \mathrm{g})$, ceftriaxone $(30 \mu \mathrm{g})$, cephalothin $(30 \mu \mathrm{g})$, chloramphenicol $(30 \mu \mathrm{g})$, ciprofloxacin $(5 \mu \mathrm{g})$, gentamicin $(10 \mu \mathrm{g})$, kanamycin $(30 \mu \mathrm{g})$, nalidixic acid $(30 \mu \mathrm{g})$, neomycin $(30 \mu \mathrm{g})$, nitrofurantoin $(100 \mu \mathrm{g})$, streptomycin $(10 \mu \mathrm{g})$, sulfisoxazole $(1000 \mu \mathrm{g})$, sulfamethoxazole + trimethoprim (23.75/ $1.25 \mu \mathrm{g})$, trimethoprim $(5 \mu \mathrm{g})$ and tetracycline $(30 \mu \mathrm{g})$. All of them were from Sensi-Discs, Becton, Dickinson and Company, Loveton, USA. The interpretation cut off points for susceptibility status of isolates was based on the CLSI guidelines [20]. For the purpose of analysis, all readings classified as intermediate were considered as resistant unless indicated. E. coli ATCC 25922 was used as a quality control organism.

\section{Statistical analysis}

Sample level prevalence of Salmonella was calculated as percentage of Salmonella culture positive fecal samples among total number of samples examined. Farm level prevalence was calculated as the percentage of farms with one or more Salmonella culture positive pooled fecal sample among the total farms sampled. Association of Salmonella detection with various factors was tested using exact test and $p$-value $<0.05$ was considered significant.

\section{Results}

Farm level Salmonella occurence with respect to various factors

Salmonella was isolated from $14.6 \%$ (7/48) of poultry farms with individual sample level prevalence of $4.7 \%$ (Table 1). Salmonella was more common in poultry farms with larger flock size and in age group of 26 months (Table 2). Majority of the farms studied contained layers or young pullets grown for egg production $(n=43,89.6 \%)$; whereas only $(n=5 ; 11.4 \%)$ were keeping broilers. Salmonella was not detected from the broiler farms. Salmonella isolation was also more common in farms of the Ada'a district as compared to other districts. Majority of the farms $(n=42 ; 87.5 \%)$ keep their birds on floor system and $12.5 \%(6 / 48)$ use cage system. Out of the farms that use cage system $33.3 \%(2 / 6)$ were positive for Salmonella whereas $11.9 \%(5 / 42)$ of farms that use floor system were found positive for Salmonella.

\section{Antimicrobials used in poultry farms}

Among the common antimicrobials, oxytetracycline was used widely in $40(83.3 \%)$ of the farms, followed by amoxicillin (29.2\%) and sulfonamides (22.9\%). Other antimicrobials such as fluoroquinolones (enrofloxacin and ciprofloxacin), and florfenicol were also used in 11 $(22.9 \%)$ and $7(14.6 \%)$ of the farms respectively, whereas $6(12.5 \%)$ of the farms reported that they did not use any antimicrobials during last 6 months. None of the farms reported use of antimicrobials as feed additive. All of the farms use antimicrobials for therapeutic or prophylactic purposes when there is one or more sick birds in the flock. Interestingly, in one of the poultry farms in Adaa district, the use of human preparation of ciprofloxacin tablet was observed. Salmonella was recovered more frequently in farms which use only amoxicillin, sulfadimidine and oxytetracycline than those farms which use fluoroquinolones and florfenicol. Recent use of antimicrobials and occurrence of Salmonella in farms is shown in Table 3. All samples from six farms with no history of use of antimicrobials were also not culture positive for Salmonella. Twenty-three (47.9\%) of the farms reported use of sodium hypochlorite disinfectant as foot bath, for cleaning poultry houses before introduction of new stock and to clean feeding utensils, while $4(8.3 \%)$ of the farms used copper sulfate. The remaining $21(43.8 \%)$ of the poultry farms were not using any disinfectant.

\section{Salmonella serotype distribution and antimicrobial susceptibility}

Salmonella Saintpaul was the dominant serotype detected in poultry farms accounting for 20 (76.9\%) of all isolates. Other serotypes, such as $S$. Typhimurium $(n=3), S$. Kentucky $(n=2)$ and $S$. Haifa $(n=1)$ were also detected. Rate of resistance to antimicrobials tested and

Table 1 Prevalence of Salmonella in poultry farms in Addis Ababa and surrounding districts

\begin{tabular}{llllll}
\hline & No. of farms & $\begin{array}{l}\text { Average no. of } \\
\text { birds /farm }\end{array}$ & No. of samples ${ }^{\text {a }}$ & $\begin{array}{l}\text { No. positive } \\
\text { samples positive }\end{array}$ & $\begin{array}{l}\text { (\%) positive } \\
\text { farms }\end{array}$ \\
\hline Ada'a & 33 & 4638 & 464 & 25 & 18.2 \\
samples
\end{tabular}

\footnotetext{
${ }^{\mathrm{a}}$ Samples were pool of fecal droppings from 3 chicken
} 
Table 2 Occurrence of Salmonella in poultry farms stratified by selected factors

\begin{tabular}{|c|c|c|c|c|}
\hline Selected Factors & No. of farms & $\begin{array}{l}\text { No. of Salmonella } \\
\text { positive farms }\end{array}$ & $\begin{array}{l}\% \text { of farms positive } \\
\text { for Salmonella }\end{array}$ & $p$-value* \\
\hline \multicolumn{5}{|l|}{ Commodity type } \\
\hline Layers & 43 & 7 & 16.3 & \multirow[t]{2}{*}{1.000} \\
\hline Broilers & 5 & 0 & 0 & \\
\hline \multicolumn{5}{|l|}{ Use of disinfectants } \\
\hline Yes & 26 & 6 & 23.1 & \multirow[t]{2}{*}{0.106} \\
\hline No & 22 & 1 & 4.5 & \\
\hline \multicolumn{5}{|l|}{ Age of birds in months } \\
\hline$<2$ & 8 & 0 & 0 & \multirow[t]{4}{*}{0.608} \\
\hline $2-6$ & 17 & 4 & 24 & \\
\hline $7-12$ & 13 & 2 & 15.4 & \\
\hline$>12$ & 10 & 1 & 10 & \\
\hline \multicolumn{5}{|l|}{ Flock size } \\
\hline$<1000$ (Small) & 22 & 2 & 9.1 & \multirow[t]{3}{*}{0.648} \\
\hline 1000-5000(Medium) & 17 & 3 & 17.7 & \\
\hline > 5000(Large) & 9 & 2 & 22.2 & \\
\hline \multicolumn{5}{|l|}{ Poultry housing system } \\
\hline Floor & 42 & 5 & 11.9 & \multirow[t]{2}{*}{0.206} \\
\hline Cage & 6 & 2 & 33.3 & \\
\hline
\end{tabular}

*Exact test was used to obtain $p$-value

resistance patterns of the isolates are shown in Tables 4 and 5 respectively. Of all the Salmonella isolates tested, $(n=24,92.3 \%)$ were resistant to sulfisoxazole and streptomycin, $(n=12,46.2 \%)$ of the isolates were resistant to cephalothin, while $(n=11,42.3 \%)$ were resistant to ampicillin, amoxicillin + clavulanic acid, kanamycin and chloramphenicol (Table 4).

Overall, multidrug resistance was commonly detected in Salmonella isolates in the current study particularly in strains belonging to $S$. Saintpaul and the two $S$. Kentucky isolates. All $S$. Saintpaul strains in the current study were isolated from farms in Ada'a district. However, there was wide diversity in their antimicrobial susceptibility pattern even among isolates obtained from the same farm. Some of them were resistant to only few antimicrobials while others were MDR to several antimicrobials. The two $S$. Kentucky isolates were resistant to 9 of the 18 antimicrobials tested (Table 5).

\section{Discussion}

Colonization of poultry with Salmonella without detectable clinical signs at farm level followed by contamination of poultry products with subsequent access to human food chain has been considered as the major sources of human salmonellosis [21, 22]. Salmonella in healthy poultry is the main risk factor for possible outbreak of human salmonellosis and epidemiological studies have shown the huge contribution of contaminated

Table 3 Recent use of antimicrobials and occurrence of Salmonella in poultry farms

\begin{tabular}{llll}
\hline $\begin{array}{l}\text { Type of Antimicrobials used during the last } \\
6 \text { months }\end{array}$ & No. of farms & $\begin{array}{l}\text { No. of Salmonella } \\
\text { positive farms }\end{array}$ & $\begin{array}{l}\text { \% of farms positive } \\
\text { for Salmonella }\end{array}$ \\
\hline Amoxicillin only & 2 & 0 & 0 \\
Oxytetracyline only & 18 & 4 & 22.2 \\
Oxytetracycline + ciprofloxacin & 3 & 0 & 0 \\
Oxytetracycline + florfenicol + enrofloxacin & 4 & 0 & 0 \\
Oxytetracycline + sulfonamides & 3 & 1 & 33.3 \\
Oxytetracycline + amoxicillin & 4 & 1 & 25 \\
Oxytetracycline + sulfonamides + amoxicillin & 8 & 1 & 12.5 \\
Did not use antimicrobial agent & 6 & 0 & 0
\end{tabular}


Table 4 Salmonella serovar distribution and rate of resistance to antimicrobial agents

\begin{tabular}{|c|c|c|c|c|c|}
\hline \multirow[t]{3}{*}{ Antimicrobial agents } & \multicolumn{4}{|c|}{$\underline{\text { Salmonella serovars and resistance rate }}{ }^{a}$} & \multirow{3}{*}{$\begin{array}{l}\text { Total No. } \\
\text { (\%) resistan }\end{array}$} \\
\hline & $\begin{array}{l}\text { S. Saintpaul } \\
(n=20)\end{array}$ & $\begin{array}{l}\text { S. Typhimurium } \\
(n=3)\end{array}$ & $\begin{array}{l}\text { S. Kentucky } \\
(n=2)\end{array}$ & $\begin{array}{l}\text { S. Haifa } \\
(n=1)\end{array}$ & \\
\hline & No. resistant (\%) & No. resistant (\%) & No. resistant (\%) & No. resistant (\%) & \\
\hline Ampicillin & $9(45)$ & 0 & $2(100)$ & 0 & $11(42.3)$ \\
\hline Amoxicillin+clavulanic acid & $9(45)$ & 0 & $2(100)$ & 0 & $11(42.3)$ \\
\hline Chloramphenicol & $10(50)$ & 0 & $1(50)$ & 0 & $11(42.3)$ \\
\hline Cephlothin & $10(50)$ & 0 & $2(100)$ & 0 & $12(46.2)$ \\
\hline Ciprofloxacin & 0 & 0 & $2(100)$ & 0 & $2(7.7)$ \\
\hline Cefoxitin & 0 & 0 & 0 & 0 & 0 \\
\hline Gentamicin & 0 & 0 & $2(100)$ & 0 & $2(7.7)$ \\
\hline Kanamycin & $8(40)$ & $2(66.7)$ & 0 & $1(100)$ & $11(42.3)$ \\
\hline Sulfamethoxazole+trimethoprim & 0 & 0 & 0 & $1(100)$ & $1(3.9)$ \\
\hline Trimethoprim & 0 & 0 & 0 & $1(100)$ & $1(3.9)$ \\
\hline Tetracycline & $4(20)$ & $1(33.3)$ & $2(100)$ & $1(100)$ & $8(30.8)$ \\
\hline Sulfisoxazole & $18(90)$ & $3(100)$ & $2(100)$ & $1(100)$ & $24(92.3)$ \\
\hline Streptomycin & $18(90)$ & $3(100)$ & $2(100)$ & $1(100)$ & $24(92.3)$ \\
\hline Nitrofurantoin & $5(25)$ & $1(33.3)$ & 0 & $1(100)$ & $7(26.7)$ \\
\hline Nalidixic acid & $2(10)$ & 0 & $2(100)$ & $1(100)$ & $5(19$ \\
\hline Neomycin & $3(15)$ & 0 & 0 & 0 & $3(11.5)$ \\
\hline
\end{tabular}

alsolates with intermediate susceptibility were also considered resistant for this analysis

poultry products to human salmonellosis [23, 24]. In fact, some countries have shown that successful control measures involving surveillance, improved biosecurity and vaccination targeting specific serovars in poultry can result in reduction of human salmonellosis cases [21, 24].

In the current study, $7(14.6 \%)$ of the 48 examined poultry farms were positive for Salmonella. This is very much low compared to studies conducted in Morocco and Nigeria where $76.7 \%$ and [25], 43.6\% [26] of the poultry farms were contaminated by Salmonella, respectively. Sample level prevalence of Salmonella was also low in the current study (4.7\%) compared to previous studies conducted elsewhere. For instance, Salmonella prevalence in fecal samples from conventional poultry farms in USA was reported to be $38.8 \%$ while it was $5.6 \%$ in organic farms [27]. Salmonella prevalence in conventional poultry is usually very high in different countries [28-31]. The possible reason for low prevalence of Salmonella in the current study could be due to the fact that most of the poultry farms in the current study were small scale farms holding small number of birds unlike most of the large commercial poultry farms where they keep thousands of birds and the feeding and management activities associated with intensification allows easy dissemination of the pathogen within the farm. This finding is in agreement with previous report where large farms were significantly associated with high prevalence of Salmonella compared to medium and small farms [32].

Both farm level and pooled sample level prevalence of Salmonella was high in farms from Ada'a district compared to other areas, which could be due to larger number of poultry farms examined from this district compared to others as well as difference in agroecology. Ada'a district is highly concentrated with large number of poultry farms and is located in rift valley which is relatively warm region compared to Addis Ababa, Sebeta and Barake districts. The fact that most of the large poultry farms in the country including the parent stocks are located in Ada'a district and most of the farms from this area shared a single serotype, $S$. Saintpaul implies the possibility of transmission of Salmonella from farm to farm in this town. Salmonella Saintpaul is not frequently isolated from poultry in other previous studies elsewhere. Salmonella Kentucky was the dominant serovar in studies conducted in Nigeria [26] and Bangladesh [31] and S. Entertidis was dominant in Spain [33]; while $S$. Typhimurium was dominant in China [34]. Although there is no serotype data on Salmonella isolates from poultry at farm level in Ethiopia, previous study from poultry food items in Addis Ababa did not report $S$. Saintpaul [35]. As most of the farms obtain their day old chickens or pullets from a few parent stock farms located in this district, there is likelihood of contamination of poultry from source farms. In addition, $S$. Saintpaul 
Table 5 Salmonella serotypes isolated from poultry farms and their antimicrobial resistance pattern

\begin{tabular}{|c|c|c|c|c|c|c|}
\hline \multirow[t]{2}{*}{ No. } & \multirow[t]{2}{*}{ Study site } & \multirow{2}{*}{$\begin{array}{l}\text { Farm } \\
\text { Code }\end{array}$} & \multirow{2}{*}{$\begin{array}{l}\text { Isolate } \\
\text { code }\end{array}$} & \multirow[t]{2}{*}{ Serotype } & \multicolumn{2}{|l|}{ Resistance pattern } \\
\hline & & & & & Intermediate & Resistant \\
\hline 1 & Adaa & DZP-20 & DP-213 T & Kentucky & C & $\begin{array}{l}\text { Amp,Amc,Cf,Cip,Gm, } \\
\text { Te,Su,S,Na }\end{array}$ \\
\hline 2 & Adaa & DZP-20 & DP-220 T & Kentucky & - & $\begin{array}{l}\text { Amp,Amc,Cf,Cip,Gm, } \\
\text { Te,Su,S,Na }\end{array}$ \\
\hline 3 & Addis Ababa & AAP-08 & $\mathrm{AP}-\mathrm{H} 2 \mathrm{O}$ & Haifa & $\mathrm{K}, \mathrm{S}$ & Sxt,Tmp,Te,Su,Nitro,Na \\
\hline 4 & Adaa & DZP-03 & DP-23 T & Saintpaul & Su & - \\
\hline 5 & Adaa & DZP-03 & Dp-24 T & Saintpaul & $\mathrm{Su}, \mathrm{S}$ & - \\
\hline 6 & Adaa & DZP-03 & $D p-25 R$ & Saintpaul & Sus & - \\
\hline 7 & Adaa & DZP-03 & DP-26R & Saintpaul & Cip,Su,SNitro,N & - \\
\hline 8 & Adaa & DZP-03 & DP-27R & Saintpaul & $\mathrm{Su}, \mathrm{S}$ & - \\
\hline 9 & Adaa & DZP-11 & DP-116 T & Typhimurium & K & $\mathrm{Te}, \mathrm{Su}, \mathrm{S}$ \\
\hline 10 & Adaa & DZP-08 & DP-70 T & Typhimurium & Sus & - \\
\hline 11 & Adaa & DZP-08 & DP-71 T & Typhimurium & K,Su,S,Nitro & - \\
\hline 12 & Adaa & DZP-33 & DP-107 & Saintpaul & $\mathrm{Amc}, \mathrm{Cf}, \mathrm{K}, \mathrm{S}$ & Amp,C,Te,Su \\
\hline 13 & Adaa & DZP-33 & DP-117 & Saintpaul & $\mathrm{Amc}, \mathrm{Cf}, \mathrm{K}, \mathrm{S}$ & Amp,C,Su \\
\hline 14 & Adaa & DZP-33 & DP-128 & Saintpaul & - & - \\
\hline 15 & Adaa & DZP-33 & DP-131 & Saintpaul & $\mathrm{K}, \mathrm{S}$ & - \\
\hline 16 & Adaa & DZP-33 & DP-110 & Saintpaul & $A m c, C f, S$ & $\mathrm{Amp}, \mathrm{C}, \mathrm{Te}, \mathrm{Su}$ \\
\hline 17 & Adaa & DZP-33 & DP-114 & Saintpaul & SuS & \\
\hline 18 & Adaa & DZP-33 & DP-126 & Saintpaul & $\mathrm{Cf}, \mathrm{S}$ & Amp,Amc,C,Su \\
\hline 19 & Adaa & DZP-12 & DP-313 & Saintpaul & $\mathrm{S}, \mathrm{K}$ & Amp,Amc,C,Cf,Te,Su \\
\hline 20 & Adaa & DZP-12 & DP-325 & Saintpaul & Amc,Cf,Su,S,Nitro & $\begin{array}{l}\text { Amp,Amc,C,Cf,Su,S, } \\
\text { Nitro,Na }\end{array}$ \\
\hline 21 & Adaa & DZP-12 & DP-327 & Saintpaul & K,S,Nitro & Su \\
\hline 22 & Adaa & DZP-12 & DP-328 & Saintpaul & Amc, Cip,S,N & Amp,C,Cf,Te,Su \\
\hline 23 & Adaa & DZP-12 & DP-339 & Saintpaul & $\mathrm{K}, \mathrm{Su}, \mathrm{S}$ & - \\
\hline 24 & Adaa & DZP-12 & DP-322 & Saintpaul & Amc,Cf, Su,S,Nitro & $\begin{array}{l}\text { Amp,Amc,C,Cf,Su,S, } \\
\text { Nitro,Na }\end{array}$ \\
\hline 25 & Adaa & DZP-12 & DP-326 & Saintpaul & $\mathrm{CF}, \mathrm{S}$ & Amp,Amc,C,Su \\
\hline 26 & Adaa & DZP-12 & DP-308 & Saintpaul & Amc,Cip,K,Su,S,Na,N & Amp,C,Cf,Nitro \\
\hline
\end{tabular}

Amp ampicillin, Amc amoxicillin and clavulanic acid, Cf cephalothin, Cip ciprofloxacin, Gm gentamicin, $K$ kanamycin, Tmp trimethoprim, Te tetracycline, Su sulfisoxazole, $S$ streptomycin, Nitro nitrofurantoin, $N a$ nalidixic acid, $N$ neomycin, -sensitive

was the major serotype detected in dairy farms in this study area which suggests possibility of transmission between dairy and poultry farms [14].

The high rate of resistance to sulfixazole and streptomycin (92.3\%) is not concordant with the current rate of use of antimicrobials in farms investigated. However, previously, different sulfonamide drugs and streptomycin together with penicillin were the common antimicrobials frequently used in the country for treatment of various infectious diseases in veterinary medicine and recent studies showed that sulfonamides and streptomycin are the 2nd and 3rd most prescribed veterinary medications respectively in the study area next to oxytetracycline [36]. Similarly, high resistance rate to ampicillin and tetracycline could be due to long term use of these antimicrobials in veterinary medicine including poultry. Interestingly, the two $S$. Kentucky isolates resistant to several drugs including nalidixic acid and ciprofloxacin were isolated from one of a few farms which reported use of fluoroquinolones for therapeutic purposes in the farm suggesting possible contribution of use of these drugs in the farm for selection of these strains. Eleven $(42.3 \%)$ of the isolates in the current study, most of which belonging to $S$. Saintpaul from farms in Ada'a district were resistant to chloramphenicol unlike previous study where all of the isolates obtained from food of animal origin including poultry products were fully susceptible to chloramphenicol [35]. Unlike previous study in south Ethiopia [11] where extremely high proportion of Salmonella isolates (97.8\%) were resistant to second generation cephalosporin (cefoxitin), in this study, none of 
the isolates were resistant to this drug. This could be due to over use of betalactam drugs in the previous farms.

\section{Conclusion}

Despite low prevalence of Salmonella in poultry farms in the study area, circulation of MDR strains in some farms warrant special biosecurity measures to hinder dissemination of these pathogens to other farms and the public. Moreover, awareness creation on prudent use of antimicrobials is recommended.

\section{Abbreviations}

BPW: Buffered peptone water; MDR: Multi-drug resistance; RVB: Rappaportvassiliadis broth; TTB: Tetrathionate broth; XLT-4: Xylose lysine tergitol 4

\section{Acknowledgments}

The author would like to thank Mr. Haile Alemayehu and Mr. Nega Nigussie for their support during sample collection and laboratory analysis. Dr. Roge P. Johnson, Dr. Linda Cole, Shaun Kernaghan, Ketna Mistry, Ann Perets and Betty Wilkie of the Public Health Agency of Canada, National Microbiology Laboratory at Guelph are also acknowledged for serotyping of Salmonella isolates.

\section{Funding}

This study was supported by WHO Advisory Group on Integrated Surveillance of Antimicrobial Resistance. The funding agency was not involved in design of study, data collection, analysis of data and manuscript writing

\section{Availability of data and materials}

All the data supporting the findings are presented in the manuscript.

\section{Author's contributions}

TE was involved in conception of the study, laboratory work, data analysis and preparation of the manuscript.

\section{Ethics approval and consent to participate}

Study was approved by Institutional Review Board of Aklilu Lemma Institute of Pathobiology, Addis Ababa University and oral consent was obtained from the farm owners before sampling.

\section{Consent for publication}

Not applicable.

\section{Competing interests}

The author declares that he has no competing interests.

\section{Publisher's Note}

Springer Nature remains neutral with regard to jurisdictional claims in published maps and institutional affiliations.

Received: 15 February 2018 Accepted: 21 June 2018

Published online: 06 July 2018

\section{References}

1. Zhao S, Datta AR, Ayers S, Friedman S, Walker RD, White DG. Antimicrobialresistant Salmonella serovars isolated from imported foods. Int J Food Microbiol. 2003;84(1):87-92

2. Foley SL, Nayak R, Hanning IB, Johnson TJ, Han J, Ricke SC. Population dynamics of Salmonella enterica serotypes in commercial egg and poultry production. Appl Environ Microbiol. 2011;77(13):4273-9.

3. Braden CR. Salmonella enterica serotype Enteritidis and eggs: a national epidemic in the United States. Clin Infect Dis. 2006:43(4):512-7.

4. Gast RK. Serotype-specific and serotype-independent strategies for preharvest control of food-borne Salmonella in poultry. Avian Dis. 2007 51(4):817-28.
5. Foley SL, Lynne AM, Nayak R. Salmonella challenges: prevalence in swine and poultry and potential pathogenicity of such isolates. J Anim Sci. 2008; 86(14 Suppl):E149-62.

6. Sivaramalingam $T$, McEwen SA, Pearl DL, Ojkic D, Guerin MT. A temporal study of Salmonella serovars from environmental samples from poultry breeder flocks in Ontario between 1998 and 2008. Can J Vet Res. 2013;77(1):1-11.

7. Wegener HC, Hald T, Lo Fo Wong D, Madsen M, Korsgaard H, Bager F, Gerner-Smidt P, Mølbak K. Salmonella control programs in Denmark. Emerg Infect Dis. 2003;9(7):774-80.

8. Hendriksen RS, Vieira AR, Karlsmose S, Lo Fo Wong DM, Jensen AB, Wegener HC, Aarestrup FM. Global monitoring of Salmonella serovar distribution from the World Health Organization global foodborne infections network country data Bank: results of quality assured laboratories from 2001 to 2007. Foodborne Pathog Dis. 2011;8(8):887-900.

9. TibaiJuka $B, B$ M, G H, J K. Occurrence of salmonellae in retail raw chicken products in Ethiopia. Berl Munch Tierarztl Wochenschr. 2003;116(1-2):55-8.

10. Endrias Z, Poppe C. Antimicrobial resistance pattern of Salmonella serotypesisolated from food items and personnel in AddisAbaba, Ethiopia. Trop Anim Prod. 2009;41:241-9.

11. Abdi RD, Mengstie F, Beyi AF, Beyene T, Waktole H, Mammo B, Ayana D, Abunna F. Determination of the sources and antimicrobial resistance patterns of Salmonella isolated from the poultry industry in southern Ethiopia. BMC Infect Dis. 2017;17(1):352.

12. Molla B, Sterman A, Mathews J, Artuso-Ponte V, Abley M, Farmer W, Rajala-Schultz P, Morrow WE, Gebreyes WA. Salmonella enterica in commercial swine feed and subsequent isolation of phenotypically and genotypically related strains from fecal samples. Appl Environ Microbiol. 2010;76(21):7188-93.

13. WHO. Who Global Foodborne Infections Network Laboratory Protocol Isolation of Salmonella spp From Food and Animal Feaces. 5th ed; 2010 http://antimicrobialresistance.dk/CustomerData/Files/Folders/6-pdfprotocols/63_18-05-isolation-of-salm-220610.pdf.

14. Eguale T, Engidawork E, Gebreyes AW, Asrat D, Alemayehu H, Medhin G, Johnson RP, Gunn JS. Fecal prevalence, serotype distribution and antimicrobial resistance of salmonellae in dairy cattle in Central Ethiopia. BMC Microbiol. 2016;16(1):1-11.

15. Cohen ND, Neibergs HL, McGruder ED, Whitford HW, Behle RW, Ray PM, Hargis BM. Genus-specific detection of salmonellae using the polymerase chain reaction (PCR). J Vet Diagn Investig. 1993;5(3):368-71.

16. Grimont PAD, Weill FX. Antigenic Formulae of the Salmonella Serovars. 9th ed. Paris: Institut Pasteur; 2007

17. Issenhuth-Jeanjean S, Roggentin P, Mikoleit M, Guibourdenche M, de Pinna E, Nair S, Fields PI, Weill FX. Supplement 2008-2010 (no. 48) to the whiteKauffmann-Le minor scheme. Res Microbiol. 2014;165(7):526-30.

18. Ewing WH. (1986) Edwards and Ewing's identification of Enterobacteriaceae, Elsevier Science Publishing Co. Inc. New York, N.Y, 4th ed.

19. Shipp CR, Rowe B. A mechanised microtechnique for salmonella serotyping J Clin Pathol. 1980;33(6):595-7.

20. CLSI: Performance Standards for Antimicrobial Susceptibility Testing; Twenty-Third Informational SupplementM100-S23. In., vol. 33; 2013.

21. Cosby DE, Cox NA, Harrison MA, Wilson JL, Buhur RJ, Fedorka-Cray PJ. Salmonella and antimicrobial resistance in broilers:A review. J Appl Poult Res. 2015;24:408-26.

22. Butaye P, Michael GB, Schwarz S, Barrett TJ, Brisabois A, White DG. The clonal spread of multidrug-resistant non-typhi Salmonella serotypes. Microbes Infect. 2006;8(7):1891-7.

23. Antunes P, Mourao J, Campos J, Peixe L. Salmonellosis: the role of poultry meat. Clin Microbiol Infect. 2016;22(2):110-21.

24. Hugas M, Beloeil P. Controlling Salmonella along the food chain in the European Union - progress over the last ten years. Euro Surveill. 2014;19(19)

25. Ziyate N, Karraouan B, Kadiri A, Darkaoui S, Soulay A. Prevalence and antimicrobial resistance of Salmonella isolates in Moroccan laying hens farms. J Appl Poult Res. 2016:25:539-46.

26. Fagbamila IO, Barco L, Mancin M, Kwaga J, Ngulukun SS, Zavagnin P, Lettini AA, Lorenzetto M, Abdu PA, Kabir J, et al. Salmonella serovars and their distribution in Nigerian commercial chicken layer farms. PLoS One. 2017 12(3):e0173097.

27. Alali WQ, Thakur S, Berghaus RD, Martin MP, Gebreyes WA. Prevalence and distribution of Salmonella in organic and conventional broiler poultry farms. Foodborne Pathog Dis. 2010;7(11):1363-71. 
28. Gaffga NH, Barton Behravesh C, Ettestad PJ, Smelser CB, Rhorer AR, Cronquist AB, Comstock NA, Bidol SA, Patel NJ, Gerner-Smidt P, et al. Outbreak of salmonellosis linked to live poultry from a mail-order hatchery. N Engl J Med. 2012;366(22):2065-73.

29. Basler C, Forshey TM, Machesky K, Erdman MC, Gomez TM, Nguyen TA, Behravesh CB. Multistate outbreak of human Salmonella infections linked to live poultry from a mail-order hatchery in Ohio-march-September 2013. MMWR Morb Mortal Wkly Rep. 2014;63(10):222.

30. Taylor M, Leslie M, Ritson M, Stone J, Cox W, Hoang L, Galanis E, Bowes V, Byrne $S$, de With $N$, et al. Investigation of the concurrent emergence of Salmonella enteritidis in humans and poultry in British Columbia, Canada, 2008-2010. Zoonoses Public Health. 2012;59(8):584-92.

31. Barua H, Biswas PK, Olsen KE, Christensen JP. Prevalence and characterization of motile Salmonella in commercial layer poultry farms in Bangladesh. PLoS One. 2012:7(4):e35914.

32. Adesiyun A, Webb L, Musai L, Louison B, Joseph G, Stewart-Johnson A, Samlal S, Rodrigo S. Survey of Salmonella contamination in chicken layer farms in three Caribbean countries. J Food Prot. 2014;77(9):1471-80.

33. Alvarez-Fernandez E, Alonso-Calleja C, Garcia-Fernandez C, Capita R. Prevalence and antimicrobial resistance of Salmonella serotypes isolated from poultry in Spain: comparison between 1993 and 2006. Int J Food Microbiol. 2012:153(3):281-7.

34. Kuang X, Hao H, Dai M, Wang Y, Ahmad I, Liu Z, Zonghui Y. Serotypes and antimicrobial susceptibility of Salmonella spp. isolated from farm animals in China. Front Microbiol. 2015;6:602.

35. Zewdu E: Prevalence, distribution and antimicrobial resistance profile of Salmonella isolated from food items and personnel in Addis Ababa, Ethiopia 2004.

36. Beyene T, Endalamaw D, Tolossa Y, Feyisa A. Evaluation of rational use of veterinary drugs especially antimicrobials and anthelmintics in Bishoftu, Central Ethiopia. BMC Res Notes. 2015;8:482.

\section{Ready to submit your research? Choose BMC and benefit from:}

- fast, convenient online submission

- thorough peer review by experienced researchers in your field

- rapid publication on acceptance

- support for research data, including large and complex data types

- gold Open Access which fosters wider collaboration and increased citations - maximum visibility for your research: over $100 \mathrm{M}$ website views per year 